\title{
Acetaldehyde Increases Dopaminergic Neuronal Activity in the VTA
}

\author{
Marzia Foddai', Gabriella Dosia', Saturnino Spiga ${ }^{2}$ and Marco Diana ${ }^{*, 1}$ \\ 'Department of Drug Sciences, University of Sassari, Sassari, Italy; ${ }^{2}$ Department of Animal Biology and Ecology, University of Cagliari, Cagliari, \\ Italy
}

\begin{abstract}
Acetaldehyde is the first and principal metabolite of ethanol administered systemically. To its rise in blood, after administration of disulfiram, is ascribed the aversive reaction that should discourage alcoholics from drinking. In the present study, we sought to determine the effect of acetaldehyde on the electrophysiological properties of dopamine (DA)-containing neurons in the ventro tegmental area (VTA) of rats in vivo. Intravenous (i.v.) administration of acetaldehyde (5-40 mg/ $/ \mathrm{kg}$ ) readily and dose-dependently increased the firing rate, spikes/burst, and burst firing of VTA neurons. Ethanol (250-1000 mg/kg/i.v.) administration produced similar increments in electrophysiological parameters. In addition, a second group of rats was pretreated with the alcohol-dehydrogenase inhibitor 4-methylpyrazole $(90 \mathrm{mg} / \mathrm{kg}$ ) intraperitoneally (i.p.), and ethanol and acetaldehyde were administered i.v. at the same doses, $48 \mathrm{~h}$ later. In this group, ethanol effects were drastically reduced and the firing rate, spikes/burst, and burst firing were not significantly altered. In contrast, acetaldehyde fully retained its capacity to stimulate electrophysiological indices. The results indicate that acetaldehyde produces electrophysiological actions on VTA neurons in vivo, similar to those produced by ethanol, and significantly participate in ethanol-induced increment in DA neuronal activity. These results also suggest that acetaldehyde, by increasing DA neuronal activity in the VTA, may significantly contribute to the centrally mediated positive motivational properties of ethanol, which would oppose the well-known peripherally originating aversive properties.

Neuropsychopharmacology (2004) 29, 530-536, advance online publication, 3 I December 2003; doi: I 0. I 038/sj.npp. I 300326
\end{abstract}

Keywords: ethanol; acetaldehyde; alcoholism; dopamine neurons; electrophysiology

\section{INTRODUCTION}

Alcoholism is a major addictive disorder with profound and far-reaching impacts on the individual and society (Goodwin and Gabrielli, 1997). Among the various pharmacological treatments available for this disorder, disulfiram (Antabuse) is the oldest (Litten et al, 1996) and perhaps most widely utilized (Fuller and Roth, 1979; Chick et al, 1992). Its mechanism of action is thought to reside in its aldehyde-dehydrogenase-inhibiting property, through which it should raise acetaldehyde blood levels, produced by ethanol ingested and metabolized by alcohol-dehydrogenase, an enzyme normally found in the gastric and hepatic tissue of human beings (Baraona et al, 1991). In turn, the augmented blood acetaldehyde concentrations are considered to be peripherally aversive (Litten et al, 1996; Eriksson, 2001) and to form the basis for the well-known

\footnotetext{
*Correspondence: Marco Diana, Department of Drug Sciences, University of Sassari, Via Muroni 23/a, 07100 Sassari, Italy, Tel: 39 070675 8052, Fax: 3979 228I2, E-mail: dsfdiana@ssmain.uniss.it Received 22 November 2002; revised 03 July 2003; accepted 28 August 2003

Online publication: 03 September 2003 at http://www.acnp.org/ citations/Npp09030302426/default.pdf
}

'flushing syndrome', commonly observed after ethanol ingestion in many orientals, an ethnic group with a low incidence of alcoholism.

On the other hand, at least some of the motivational properties of ethanol are thought to be mediated by the mesolimbic dopamine (DA) system, whose cell bodies are located in the ventro tegmental area (VTA) of the midbrain (see Diana and Tepper, 2002, for a recent review). Accordingly, acute ethanol administration increases the electrophysiological activity of these neurons in vivo (Gessa et al, 1985) and in vitro (Brodie et al, 1990), and augments DA microdialysate concentrations in terminal areas (Imperato and Di Chiara, 1986) of freely behaving rats. Conversely, ethanol withdrawal decreases dopaminergic neuronal activity in rats in vivo (Diana et al, 1993) and mice in vitro (Bailey et al, 1998), and reduces DA extracellular concentrations in the nucleus accumbens (Rossetti et al, 1992; Diana et al, 1993; Weiss et al, 1996). All these studies have suggested that both positive (reinforcing) and negative (dysphoriant) properties induced by acute ethanol and its withdrawal, respectively, are mediated, at least partially, by increments and decrements of DA neurons activity projecting to the nucleus accumbens (Diana, 1996, 1998; Pulvirenti and Diana, 2001; Diana and Tepper, 2002). 
In contrast, studies suggest that acetaldehyde may participate in the positive motivational properties of ethanol (Eriksson, 2001; Aragon et al, 1986). Accordingly, acetaldehyde is readily self-administered intravenously (i.v.) (Myers et al, 1982, 1984), directly into the VTA (RoddHenricks et al, 2002) and into the cerebral ventricles (Brown et al, 1979, 1980). Further, when administered intracerebroventricularly, acetaldehyde is able to induce place preference in rats (Smith et al, 1984) and to produce a conditioned stimulus preference, even when administered peripherally (Quertemont and De Witte, 2001). All these studies lend support to the hypothesis that acetaldehyde may contribute to the central actions of ethanol.

In the present study, we sought to determine directly if acetaldehyde administration alters DA neuronal activity in the VTA, and if this action bears any relationship with exogenously administered ethanol. To this aim, we blocked ethanol metabolism with the alcohol-dehydrogenase inhibitor 4-methyl-pyrazole (4-MP) and studied the effect of ethanol and acetaldehyde on the electrophysiological properties of rat DA-containing VTA neurons in vivo, with extracellular single-unit recording techniques.

\section{MATERIALS AND METHODS}

\section{Subjects and Treatments}

Male Sprague-Dawley albino rats (200/300 g) were used in all experiments. All subjects were kept on a $12 \mathrm{~h} / 12 \mathrm{~h}$ light/ dark cycle with food and water ad libitum. Experimental protocols were performed in strict accordance with the European Community regulations for the use of experimental animals (CEE No 86/609), and the recommended guidelines for the care and use of experimental animals approved by the Society for Neuroscience. Rats were randomly assigned to the following groups: (1) ALD $(n=19)$ that received exponentially increasing doses (5$40 \mathrm{mg} / \mathrm{kg} /$ i.v. $)$ of acetaldehyde. (2) ETH $(n=10)$ that received exponentially increasing doses of ethanol (250$1000 \mathrm{mg} / \mathrm{kg} / \mathrm{i.v.})$. (3) 4-MP-ETH $(n=10)$ that received a single dose of the alcohol-dehydrogenase-inhibitor 4-MP $(90 \mathrm{mg} / \mathrm{kg} / \mathrm{i} . \mathrm{p}$.$) dissolved in saline and ethanol (250-$ $1000 \mathrm{mg} / \mathrm{kg} / \mathrm{i.v}$.) $48 \mathrm{~h}$ later. (4) $4-\mathrm{MP}-\mathrm{ALD}(n=10)$ that received a single dose of the alcohol-dehydrogenaseinhibitor 4-MP (90 mg/kg/i.p.) dissolved in saline and acetaldehyde (5-40 mg/kg/i.v.) $48 \mathrm{~h}$ later. Controls (CTRL) $(n=9)$ received an equal volume $(0.1 \mathrm{ml} / \mathrm{hg}$ of body weight $)$ of vehicle (saline i.p.) and $48 \mathrm{~h}$ later ethanol $(n=4)$ or acetaldehyde $(n=5)$. Drugs were administered $48 \mathrm{~h}$ after 4-MP because previous studies (Waller et al, 1982) showed its maximum efficacy in reducing spontaneous ethanol intake at this time.

All groups underwent identical surgical procedure. Subjects were anesthetized with urethane $(1.3 \mathrm{~g} / \mathrm{kg})$ i.p., the femoral vein was exposed, and a catheter inserted into the lumen to allow i.v. administration of pharmacological agents.

\section{Electrophysiological Recordings}

Rats were mounted on a stereotaxic apparatus (Kopf, Tujunga, CA, USA) and prepared as follows: the scalp was retracted and a hole was drilled in the skull for the placement of a recording electrode filled with $2 \%$ pontamine sky blue (PSB) in $0.5 \mathrm{M} \mathrm{NaCl}$, above the VTA (AP 1.8/2.0 from lambda; L 0.2/0.5 from midline) (Paxinos and Watson, 1997). Presumptive dopaminergic neurons were identified according to well-established electrophysiological characteristics, that is, action potentials with biphasic or triphasic waveforms greater than $2.5 \mathrm{~ms}$ in duration, a typically slow spontaneous firing rate $(2-5 \mathrm{~Hz})$, and occurrence of single and burst spontaneous firing pattern. The extracellular neuronal signal from single neurons was amplified (Neurolog System) and displayed on a digital oscilloscope (Tektronix TDS 3012) before storage on a magnetic tape for off-line analysis of the data. Data were logged on a standard PC computer through CED 1401 interface, and firing rate and pattern analysis were performed by CED Spike2 system utilizing firing rate histograms generated by CED Spike2 software. A burst was defined according to Grace and Bunney (1984) as a train of at least two spikes with the first interspike interval of $80 \mathrm{~ms}$ or less, and a termination interval greater than or equal to $160 \mathrm{~ms}$. Burst activity was analyzed according to the total percent of firing occurring in bursts called percentage of bursts, and by the mean number of spikes within a burst (Diana et al, 1989). The analysis of these parameters (spikes/s, spikes/burst, and percentage of burst firing) is an important index for the activity of DA cells (Overton and Clark, 1997; Cooper, 2002), and allows one to evaluate carefully the influences that a putative drug exerts on the cell discharge pattern. After $5 \mathrm{~min}$ of stable neuronal recording (basal activity), exponentially increasing doses of ethanol $(0.25 / 0.25 / 0.5 \mathrm{~g} / \mathrm{kg})$ or acetaldehyde $(5 / 5 / 10 / 20 \mathrm{mg} / \mathrm{kg})$ were injected i.v. every $2 \mathrm{~min}$, so that the last administered dose was equal to the sum of the drug already received, and the cell activity was recorded. Only one cell was recorded per rat. Drug-induced modifications of the basal activity were calculated in percentage for the 2-min period following each administration and compared with the predrug baseline. Statistical significance of the data was evaluated by one-way analysis of variance for repeated measures (ANOVA). At the end of each recording section, DC current $(5 \mu \mathrm{A}$ for $15 \mathrm{~min})$ was passed through the recording electrode in order to eject Pontamine sky blue, which allowed the identification of the location of the recorded cells. Brains were removed and fixed in $8 \%$ formalin solution. The position of the electrodes was microscopically verified on sections $(60 \mu \mathrm{m})$ stained with Cresyl violet (Figure 1).

\section{RESULTS}

A total of 58 neurons were recorded and included in the present study. The effect of acetaldehyde on VTA dopaminergic neuronal activity was studied in a total of 19 VTA neurons. In 13 cases, acetaldehyde was administered up to a cumulative dose of $20 \mathrm{mg} / \mathrm{kg} / \mathrm{i}$.v., and in the remaining six neurons a cumulative dose of $40 \mathrm{mg} / \mathrm{kg}$ was injected. Since no statistical difference was found, basal activity values were pooled and analyzed for differences between pre- and postacetaldehyde. 


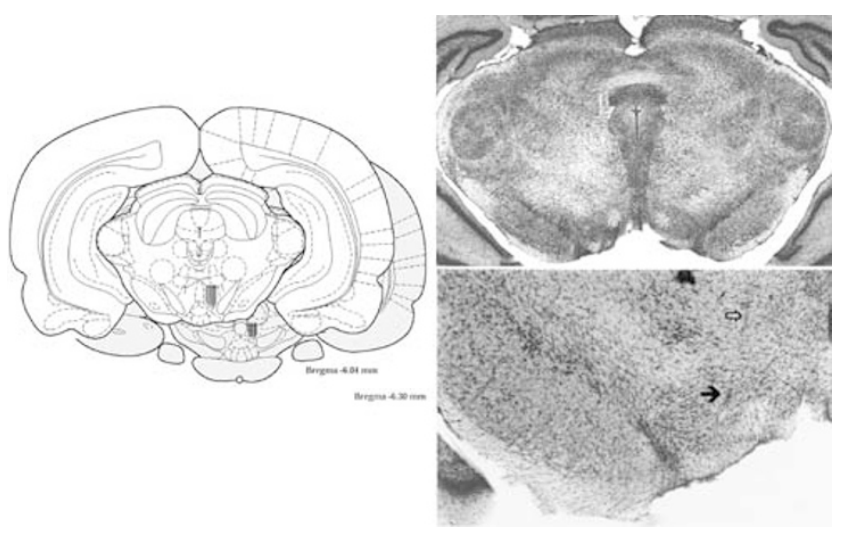

Figure I Placements of the electrodes illustrating various recording sites in the ventral mesencephalon. Left: the schemes represent regions of the mesencephalon from which all recordings were obtained. Vertical bars in the VTA indicate the position of the electrodes. Right (top): low $(\times 5)$ magnification of a cresyl violet-stained slice of a rat from which a VTA-DA neuron included in the present study was recorded. Bottom: high magnification $(\times 100)$ of the ventral mesencephalon marked by PSB (filled arrow) indicating the recording site. The open arrow indicates red blood cells in the electrode track.

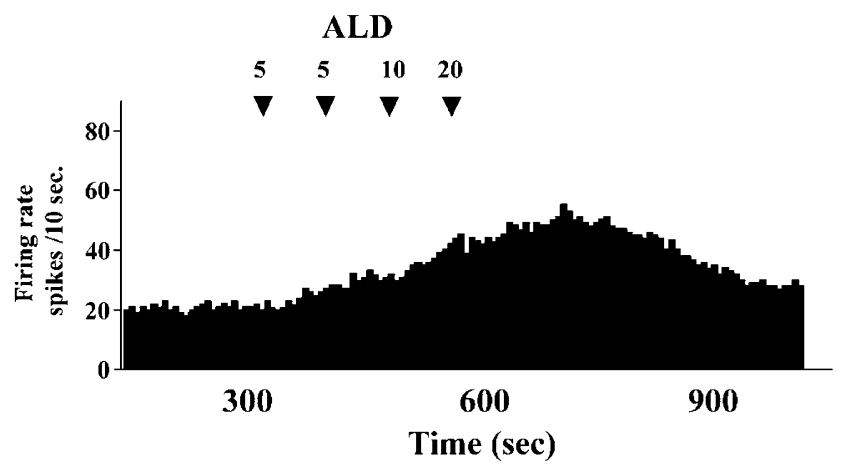

Figure 2 Example of the effect of acetaldehyde (ALD) on a VTA neuron. The firing rate histogram depicts the dose-response effect for a total dose administered of $40 \mathrm{mg} / \mathrm{kg}$. Arrows indicate the timing of administration. Numbers above arrows indicate dosage expressed in $\mathrm{mg} / \mathrm{kg}$.

The baseline firing rate was $3.08 \pm 0.25$ (mean \pm SEM) and it was readily increased dose-dependently in all neurons tested by i.v. acetaldehyde administration. An example is given in Figure 2, in which a cumulative dose of $40 \mathrm{mg} / \mathrm{kg}$ was administered. Acetaldehyde administration also produced an increment in the number of spikes contained in each burst (spikes/burst) and in the percentage of spikes delivered in bursts (burst/firing) Figure 3.

As expected, i.v. ethanol administration $(0.125-1 \mathrm{~g} / \mathrm{kg})$ $(n=10)$ produced increments in all three parameters studied, in all cells, of a magnitude similar to that induced by acetaldehyde administration. An example of its effect on the firing rate is given in Figure 4, in which a cumulative dose of $1 \mathrm{~g} / \mathrm{kg}$ was administered. In addition, parallel increases in spikes/burst, and in the percentage of burst firing were observed, and are shown in Figure 5. Onset of action of the two drugs (ethanol and acetaldehyde) was evaluated by measuring the time between the onset of drug administration and the first 10 -s epoch, in which the firing rate increased at least $10 \%$ above baseline. Statistical evaluation did not reach the level of significance $(p>0.05)$.
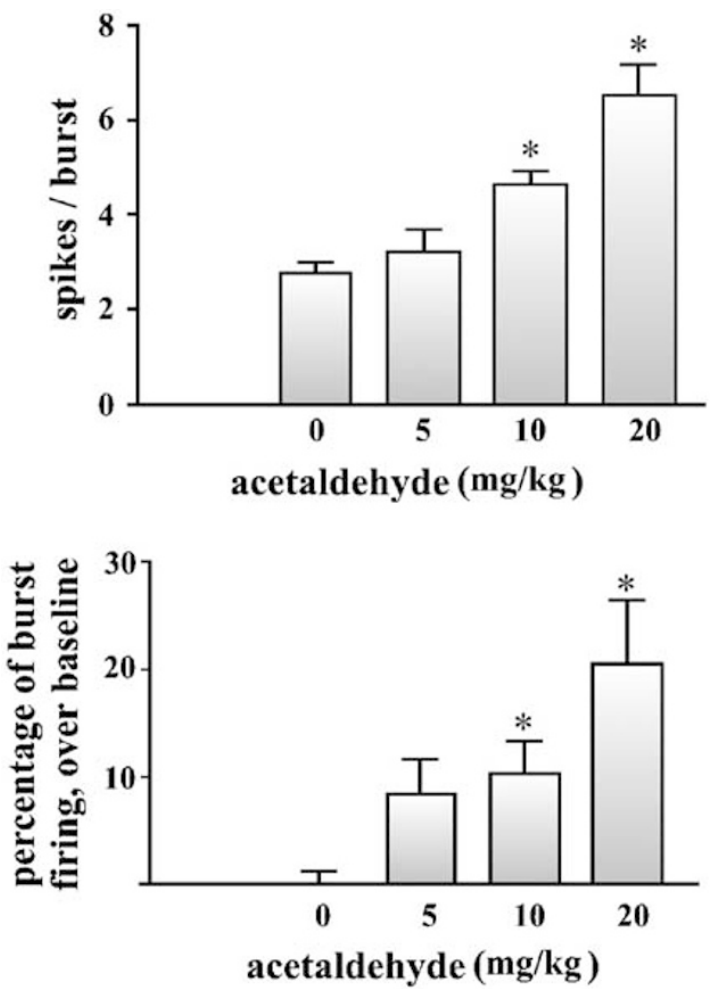

Figure 3 Top: effect of i.v. cumulative doses of acetaldehyde (ALD) on the number of spikes/burst in a total of 19 VTA neurons studied. The dosedependent increment is statistically significant at the doses of 10 and $20 \mathrm{mg} /$ $\mathrm{kg}, p<0.01$. Bottom: effect of cumulative doses of acetaldehyde (ALD) on burst firing of VTA neurons. The dose-dependent increase is statistically significant at doses of 10 and $20 \mathrm{mg} / \mathrm{kg}, p<0.01$. Results are presented as mean \pm SEM. The 0 value represents predrug baseline values in both panels.

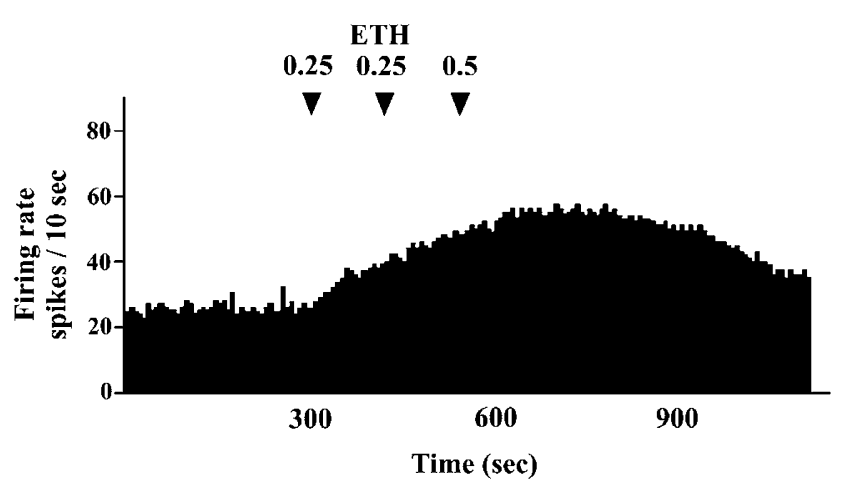

Figure 4 Example of the effect of ethanol (ETH) on a VTA neuron. The firing rate histogram depicts the dose-response effect for a total dose administered of $\mathrm{Ig} / \mathrm{kg}$. Arrows indicate the timing of administration. Numbers above arrows indicate dosage expressed in $\mathrm{g} / \mathrm{kg}$.

In order to gain some further insight into the relative contribution of the two drugs (ie acetaldehyde and ethanol) to the activation of VTA neurons, an additional group of rats $(n=20)$ was pretreated with the ADH-inhibitor 4-MP (Waller et al, 1982). Ethanol $(n=10)$ was then administered to 4-MP-pretreated rats and relative CTRL (pretreated with saline) $(n=4)$ at the same doses administered in normal (untreated) animals. Ethanol-stimulating capacity upon 

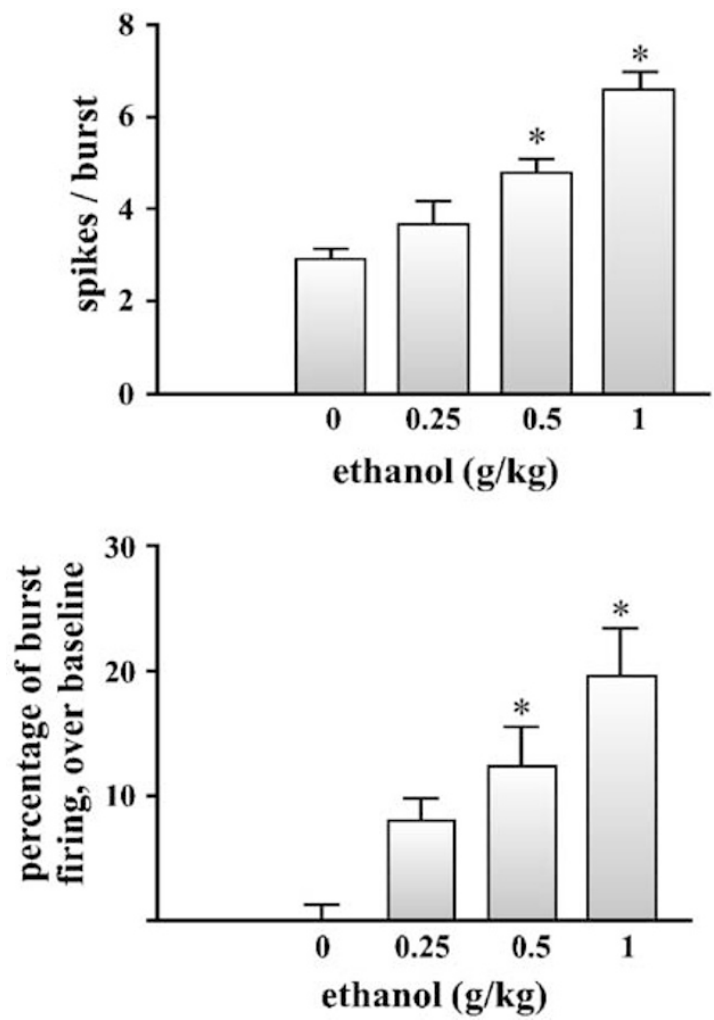

Figure 5 Top: effect of i.v. cumulative doses of ethanol (ETH) on the number of spikes/burst in a total of I0 VTA neurons studied. The dosedependent increment is statistically significant at doses of 0.5 and $1 \mathrm{~g} / \mathrm{kg}$, $p<0.01$. Bottom: effect of ethanol (ETH) on burst firing of VTA neurons. The dose-dependent increase is statistically significant at doses of 0.5 and $\mathrm{l} g / \mathrm{kg}, p<0.0 \mathrm{l}$. Results are presented as mean $\pm \mathrm{SEM}$. The 0 value represents predrug baseline values in both panels.

VTA neuronal activity was significantly reduced in 4-MPpretreated rats, and the firing rate activity was never observed to increase above $5 \%$ of the predrug values, whereas it was fully retained in CTRL rats (Figure 6).

In contrast, acetaldehyde administration increased neuronal activity in 4-MP-pretreated rats $(n=10)$ to a degree similar to that observed in untreated and CTRL (vehiclepretreated) rats $(n=5)$ (Figure 7$)$. These effects were observed to varying degrees in all neurons tested.

Figure 8 illustrates the dose-response curves for acetaldehyde and ethanol obtained from 4-MP-pretreated rats and relative CTRL.

\section{DISCUSSION}

The main finding of the present study is that acetaldehyde dose-dependently increases the firing rate and burst firing of VTA neurons in a manner similar to ethanol-induced increase of VTA neuronal activity (Mereu et al, 1984; Gessa et al, 1985; Brodie et al, 1990; present results). Furthermore, the results presented here suggest that the enhancement of dopaminergic transmission after ethanol administration (Gessa et al, 1985; Brodie et al, 1990) might be at least partially mediated by acetaldehyde. Accordingly, acetalde-
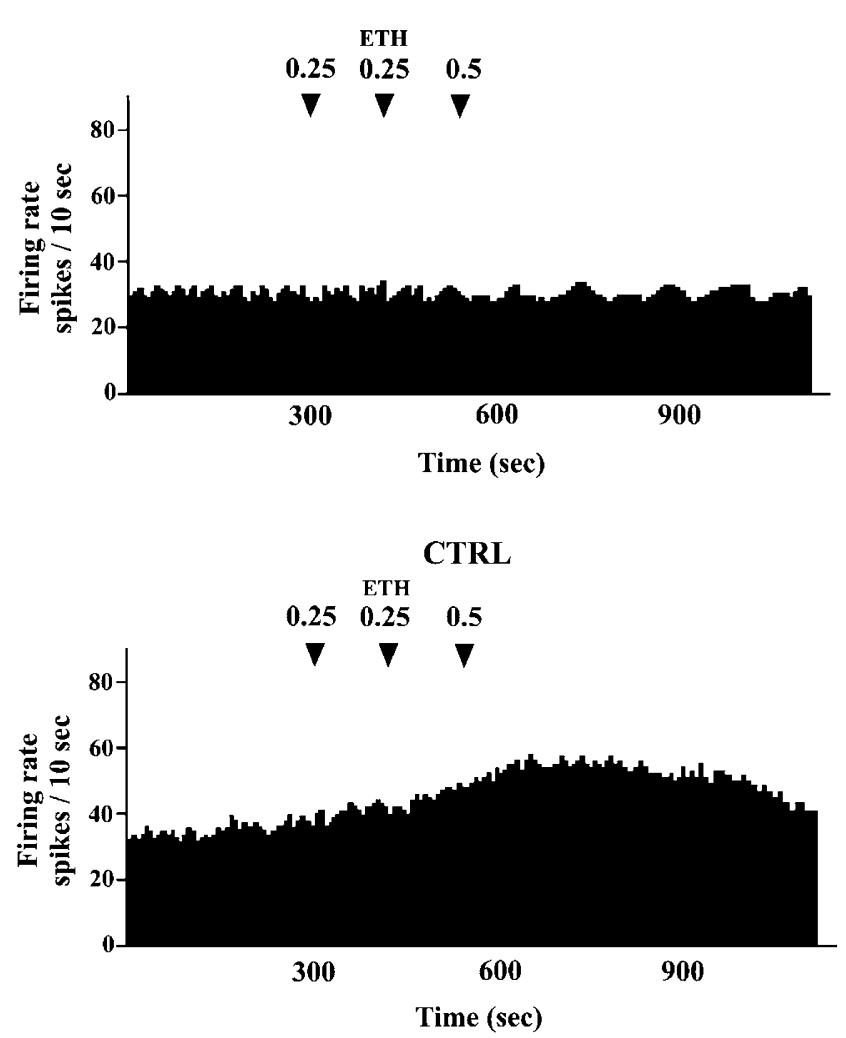

Figure 6 Top: example of the effect of i.v. ethanol (ETH) on a VTA neuron recorded from a rat pretreated with 4-MP. The firing rate histogram depicts the lack of effect for a total dose of I g/ kg administered. Arrows indicate the timing of administration. Numbers above arrows indicate dosage expressed in $\mathrm{g} / \mathrm{kg}$. Bottom: example of the effect of i.v. ethanol (ETH) on a VTA neuron recorded from a CTRL rat (vehicle pretreated). The firing rate histogram depicts the dose-dependent stimulating effect for a total dose administered of $1 \mathrm{~g} / \mathrm{kg}$. Arrows indicate the timing of administration. Numbers above arrows indicate dosage expressed in $\mathrm{g} / \mathrm{kg}$.

hyde administered alone, like ethanol, readily and dosedependently increased the firing rate, spikes/burst, and burst firing of DA-containing neurons of the VTA, a brain region that is known to be involved in the motivational properties of drugs of abuse in general, including ethanol (see Pulvirenti and Diana, 2001; Diana and Tepper, 2002 for recent reviews). In addition, acetaldehyde stimulated the electrophysiological activity of VTA-DA neurons in animals in which ethanol metabolism was pharmacologically blocked by the ADH-inhibitor 4-MP, whereas this ethanol property was significantly reduced under this condition. This experiment suggests that conversion of ethanol into acetaldehyde, presumably by $\mathrm{ADH}$, is an important step, although not the only one, to observe an enhancement of DA transmission after ethanol administration. However, this conclusion is based on the use of 4-MP only and additional experiments with structurally different ADHinhibitors and catalase inhibitors are needed to draw definitive conclusions and to ascertain the relative role of these enzymes in the genesis of the results observed here. Further, acetaldehyde $(5 \mu \mathrm{M})$ produces an inward current in DA neurons recorded in vitro in the whole-cell configuration of the patch clamp technique (Melis and Bonci, personal communication), suggesting a direct effect, induced by acetaldehyde, on the membrane of DA neurons. 

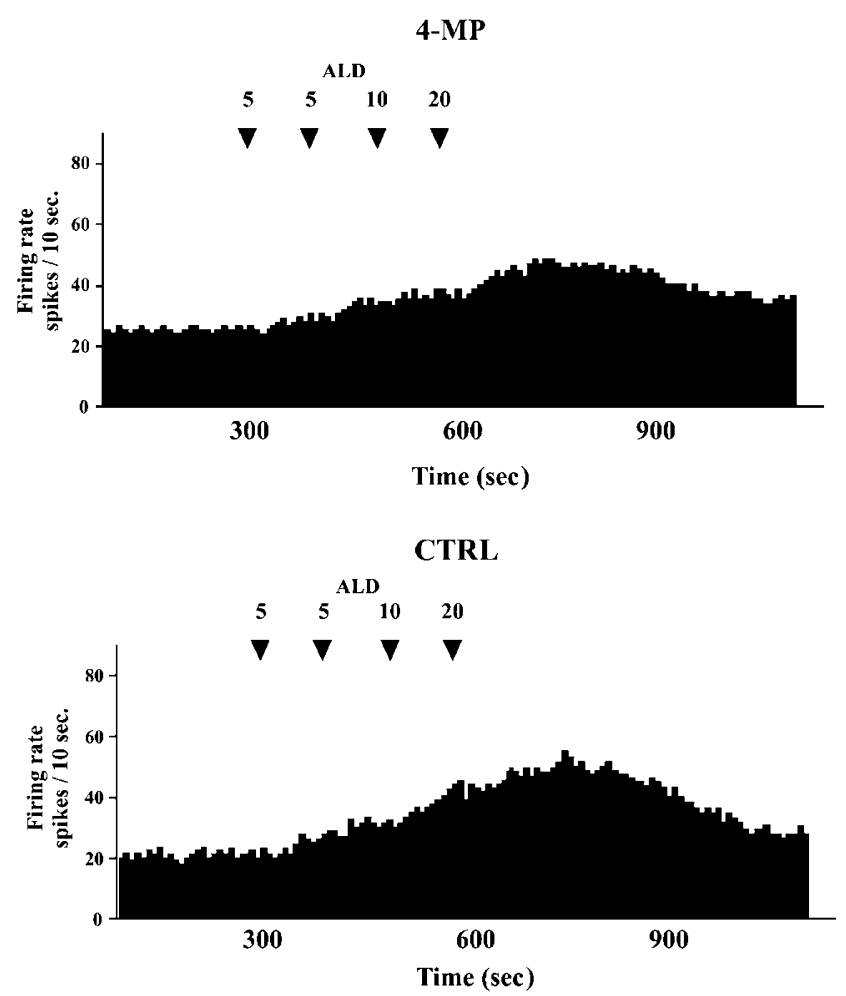

Figure 7 Top: example of the effect of i.v. acetaldehyde (ALD) on a VTA neuron recorded from a rat pretreated with 4-MP. The firing rate histogram depicts the dose-dependent effect for a total dose administered of $40 \mathrm{mg} / \mathrm{kg}$. Arrows indicate the timing of administration. Numbers above arrows indicate dosage expressed in $\mathrm{mg} / \mathrm{kg}$.

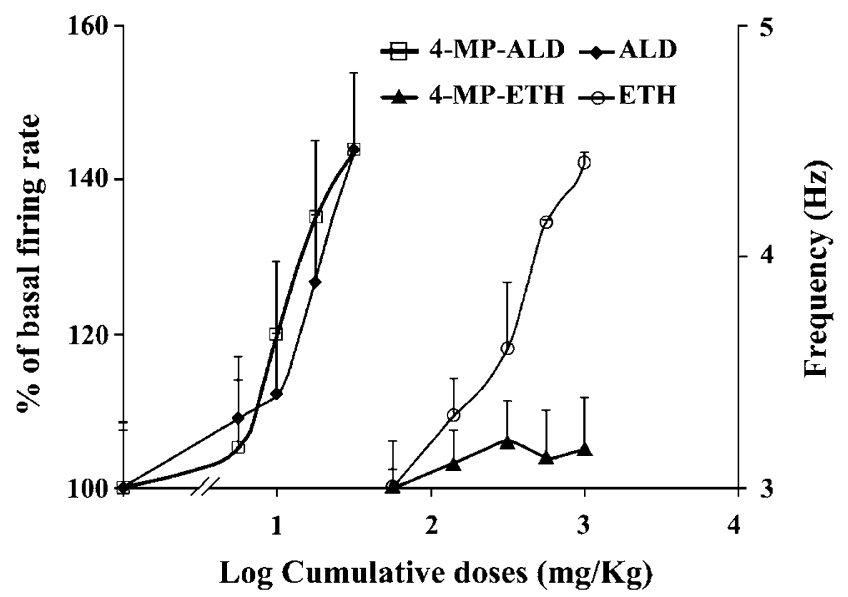

Figure 8 Dose-response curves for acetaldehyde (ALD) and ethanol (ETH) depicting the stimulatory effect of cumulative doses of both drugs on the firing rate of VTA neurons recorded from 4-MP-pretreated rats and CTRL. Note that ethanol (ETH) effect is lost in rats in which ethanol (ETH) metabolism is pharmacologically blocked (4-MP-ETH). 4-MP-ALD vs ALD are not significantly different $(p>0.05)$, whereas 4-MP-ETH and ethanol $(E T H)$ are significantly $(p<0.0 \mathrm{I})$ different. ANOVA for repeated measures. Right $Y$-axis depicts the gross firing rate in Hertz $(\mathrm{Hz})$. Left $Y$-axis depicts percentage of increase over baseline.

More experiments need to be performed in order to ascertain with certainty the primary cellular target of the acetaldehyde-induced increment in DA neuronal firing and pattern observed here. Likewise, additional work is required to extend these observations to higher doses of acetaldehyde, not tested in the present study. Indeed, we cannot exclude, based on the present results, that higher concentrations of acetaldehyde may not influence dopaminergic activity, or may even reduce it, as suggested by microdialysis studies (Ward et al, 1997, see below). Alternatively, the lack of increment in DA neuronal activity after ethanol in 4-MP-pretreated rats could be due to the accumulation in blood ethanol levels produced by pharmacological blockade of ADH. Accordingly, Waller et al (1982) reported that $48 \mathrm{~h}$ after 4-MP administration, blood ethanol levels rise more than six times, as compared with predrug values, while spontaneous ethanol drinking is comparatively reduced. In turn, high ethanol doses $(>1 \mathrm{~g} / \mathrm{kg} /$ i.v. $)$ do not stimulate DA neuronal activity (Gessa et al, 1985), but produce a slow and steady reduction in firing rate even in nigral DA neurons (Mereu et al, 1984) in anesthetized rats.

On the other hand, these results add significantly to a growing body of evidence that lends support to the fact that acetaldehyde might be an active metabolite of ethanol in the euphoriant properties of alcoholic beverages (Quertemont et al, 2003) through an activation of DA neurons in the VTA. Indeed, acetaldehyde is self-administered directly into the posterior VTA of rats selected for spontaneous alcohol preference (Rodd-Henricks et al, 2002), resulting in being 1000 times more potent than ethanol (Rodd-Henricks et al, 2000 ) in this paradigm, and into the cerebral ventricles of unselected rodents (Brown et al, 1979). In addition, acetaldehyde produces place preference when administered intracerebroventricularly (Smith et al, 1984), and produces a conditioned stimulus preference even when administered peripherally (Quertemont and De Witte, 2001) at doses similar to those employed here. All these reports suggest a positive motivational role for acetaldehyde, whereas the latter evidence (Quertemont and De Witte, 2001) would tend to exclude the possibility that acetaldehyde is reaching the brain because of an altered permeability of the bloodbrain barrier, as in the present experiments, since the compound was administered peripherally (Quertemont and De Witte, 2001) and the blood-brain barrier was thus left intact. However, in contrast, microdialysis experiments (Ward et al, 1997) have reported a decrease in DA microdialysate in the nucleus accumbens instead of the anticipated increment predicted by the present reasoning. The reasons for this discrepancy are presently unknown, although recent reports have suggested that microdialysate DA could be overshadowed by DA originating from noradrenergic terminals (Devoto et al, 2002) in brain areas in which the two projections coexist. Since the nucleus accumbens, in particular its shell subdivision, possesses a significant noradrenergic projection (Berridge et al, 1997), these experiments should be interpreted cautiously.

It would remain to be explained how ethanol increases DA firing when recorded in slices in vitro (Brodie et al, 1990, 1999). In this experimental setting, ethanol conversion into acetaldehyde might take place through catalase, which is known to be present in the brain (McBride et al, 2002; Zimatkin and Lindros, 1996; Quertemont et al, 2003) and should be functionally preserved by the slice sectioning procedure. Consistent with this possibility is the fact that very high doses of ethanol, that is, $80-120 \mathrm{mM}$, are required to observe a modest (ca 10\%) ethanol-induced excitation of 
DA neurons in vitro (Brodie et al, 1990, 1999) as compared with larger increments observed in vivo in unanesthetized (Gessa et al, 1985) and urethane-anesthetized rats (present results).

These results may also bear important theoretical consequences on the therapeutic side of alcoholism (Litten et al, 1996; Fadda and Rossetti, 1998) and drug addiction in general. Indeed, according to the present results, blockade of ethanol metabolism should largely deprive ethanol of its positive reinforcing properties and, possibly, discourage individuals from intake. Accordingly, 4-MP, at the doses and timing employed here, has been found to be effective in reducing spontaneous alcohol intake in rodent lines selected for high alcohol preference (Waller et al, 1982), a predictor of potentially valuable therapeutic compounds. In addition, the blockade of catalase with 3-amino-1,2,4-triazole also reduces spontaneous ethanol drinking (Aragon and Amit, 1992) and potentiates conditioned taste aversion induced by ethanol, because of a reduction in brain acetaldehyde (Quertemont et al, 2003). This would suggest that a reduced metabolism of drugs of abuse, either pharmacologically obtained or genetically determined (Tyndale et al, 1999), may reduce the risk of addiction.

In conclusion, the present results suggest that acutely administered acetaldehyde, in vivo, stimulates dopaminergic neuronal activity in the VTA. Consistently, 4-MP pretreatment prevented ethanol-induced stimulation of VTA firing, suggesting that acetaldehyde might significantly participate in ethanol-induced increments in VTA neuronal activity. These results may be relevant in explaining the neural basis of acetaldehyde intra-VTA self-administration (Rodd-Henricks et $a l, 2002$ ) and the reduction in ethanol drinking observed after 4-MP pretreatment (Waller et al, 1982). While additional experiments employing structurally different $\mathrm{ADH}$-inhibitors are warranted to generalize these conclusions, the present results suggest that pharmacological impairment of ethanol metabolism requires further experimental testing as a possible new therapeutic strategy in alcohol abuse and alcoholism.

\section{ACKNOWLEDGEMENTS}

This work was supported in part by a grant from MIUR to MD. We thank Delia Macciotta and Daniela Lampis for their expert technical assistance and William Dunn III for proofreading the manuscript.

\section{REFERENCES}

Aragon CM, Abitbol M, Amit Z (1986). Acetaldehyde may mediate reinforcement and aversion produced by ethanol. An examination using a conditioned taste-aversion paradigm. Neuropharmacology 25: 79-83.

Aragon CM, Amit Z (1992). The effect of 3-amino-1,2,4-triazole on voluntary ethanol consumption: evidence for brain catalase involvement in the mechanism of action. Neuropharmacology 31: 709-712.

Bailey CP, Manley SJ, Watson WP, Wonnacott S, Molleman A, Little HJ (1998). Chronic ethanol administration alters activity in ventral tegmental area neurons after cessation of withdrawal hyperexcitability. Brain Res 803: 144-152.

Baraona E, Yokoyama A, Ishii H, Hernandez-Munoz R, Takagi T, Tsuchiya $M$ et al (1991). Lack of alcohol dehydrogenase isoenzyme activities in the stomach of Japanese subjects. Life Sci 49: 1929-1934.

Berridge CW, Stratford TL, Foote SL, Kelley AE (1997). Distribution of dopamine beta-hydroxylase-like immunoreactive fibers within the shell subregion of the nucleus accumbens. Synapse 27: 230-241.

Brodie MS, Shefner SA, Dunwiddie TV (1990). Ethanol increases the firing rate of dopamine neurons of the rat ventral tegmental area in vitro. Brain Res 508: 65-69.

Brodie MS, McElvain MA, Bunney EB, Appel SB (1999). Pharmacological reduction of small conductance calciumactivated potassium current (SK) potentiates the excitatory effect of ethanol on ventral tegmental area dopamine neurons. J Pharmacol Exp Ther 290: 325-333.

Brown ZW, Amit Z, Rockman GE (1979). Intraventricular selfadministration of acetaldehyde, but not ethanol, in naïve laboratory rats. Psychopharmacology (Berl) 64: 271-276.

Brown ZW, Amit Z, Smith BR (1980). Intraventricular selfadministration of acetaldehyde and voluntary consumption of ethanol in rats. Behav Neural Biol 28: 150-155.

Chick J, Gough K, Falkowski W, Kershaw P, Hore B, Mehta B et al (1992). Disulfiram treatment of alcoholism. Br J Psychiatry 161: 84-89.

Cooper DC (2002). The significance of action potential bursting in the brain reward circuit. Neurochem Int 41: 333-340.

Devoto P, Flore G, Pira L, Diana M, Gessa GL (2002). Co-release of noradrenaline and dopamine in the prefrontal cortex after acute morphine and during morphine withdrawal. Psychopharmacology (Berl) 160: 220-224.

Diana M (1996). Dopaminergic neurotransmission and drug withdrawal: relevance to drug craving. In: Ohye C, Kimura M, McKenzie J (eds). The Basal Ganglia V. Advances in Behavioral Biology 47. Plenum Press: New York. pp 123-130.

Diana M (1998). Drugs of abuse and dopamine cell activity. $A d v$ Pharmacol 42: 998-1001.

Diana M, Tepper JM (2002). Electrophysiological pharmacology of mesencephalic dopaminergic neurons. In: G Di Chiara (ed). Handbook of Experimental Pharmacology 154/II. SpringerVerlag: Berlin, Heidelberg. pp 1-62.

Diana M, Garcia-Munoz M, Richards J, Freed CR (1989). Electrophysiological analysis of dopamine cells from the substantia nigra pars compacta of circling rats. Exp Brain Res 74: 625-630.

Diana M, Pistis M, Carboni S, Gessa GL, Rossetti ZL (1993). Profound decrement of mesolimbic dopaminergic neuronal activity during ethanol withdrawal syndrome in rats: electrophysiological and biochemical evidence. Proc Natl Acad Sci USA 90: 7966-7969.

Eriksson CJ (2001). The role of acetaldehyde in the actions of alcohol (update 2000). Alcohol Clin Exp Res 25: 15S-32S; review.

Fadda F, Rossetti ZL (1998). Chronic ethanol consumption: from neuroadaptation to neurodegeneration. Prog Neurobiol 56: 385-431.

Fuller RK, Roth HP (1979). Disulfiram for the treatment of alcoholism. An evaluation in 128 men. Ann Intern Med 90: 901-904.

Gessa GL, Muntoni F, Collu M, Vargiu L, Mereu G (1985). Low doses of ethanol activate dopaminergic neurons in the ventral tegmental area. Brain Res 348: 201-203.

Goodwin DW, Gabrielli WF (1997). Alcohol: clinical aspects. In: Lowinson JH, Ruiz P, Millman RB, Langrod JG (eds). Substance Abuse: A Comprehensive Textbook 3rd edn. Williams \& Wilkins: Baltimore, MD. pp 142-148.

Grace AA, Bunney BS (1984). The control of firing pattern in nigral dopamine neurons: burst firing. J Neurosci 4: 2877-2890.

Imperato A, Di Chiara G (1986). Preferential stimulation of dopamine release in the nucleus accumbens of freely moving rats by ethanol. J Pharmacol Exp Ther 239: 219-228. 
Litten RZ, Allen J, Fertig J (1996). Pharmacotherapies for alcohol problems: a review of research with focus on developments since 1991. Alcohol Clin Exp Res 20: 859-876.

McBride WJ, Li TK, Deitrich RA, Zimatkin S, Smith BR, RoddHenricks ZA (2002). Involvement of acetaldehyde in alcohol addiction. Alcohol Clin Exp Res 26: 114-119.

Mereu G, Fadda F, Gessa GL (1984). Ethanol stimulates the firing rate of nigral dopaminergic neurons in unanesthetized rats. Brain Res 292: 63-69.

Myers WD, Ng KT, Singer G (1982). Intravenous self-administration of acetaldehyde in the rat as a function of schedule, food deprivation and photoperiod. Pharmacol Biochem Behav 17: 807-811.

Myers WD, Ng KT, Singer G (1984). Ethanol preference in rats with a prior history of acetaldehyde self-administration. Experientia 40: $1008-1010$

Overton PG, Clark D (1997). Burst firing in midbrain dopaminergic neurons. Brain Res Rev 25: 312-334.

Paxinos G, Watson C (1997). The Rat Brain in Stereotaxic Coordinates compact 3rd edn Academic Press, New York.

Pulvirenti L, Diana M (2001). Drug dependence as a disorder of neural plasticity: focus on dopamine and glutamate. Rev Neurosci 12: 41-59.

Quertemont E, De Witte P (2001). Conditioned stimulus preference after acetaldehyde but not ethanol injections. Pharmacol Biochem Behav 68: 449-454.

Quertemont E, Escarabajal MD, De Witte P (2003). Role of catalase in ethanol-induced conditioned taste aversion: a study with 3-amino-1,2,4-triazole. Drug Alcohol Depend 70: 77-83.

Rodd-Henricks ZA, Melendez RI, Zaffaroni A, Goldstein A, McBride W, Li TK (2002). The reinforcing effects of acetaldehyde in the posterior ventral tegmental area of alcohol preferring rats. Pharmacol Biochem Behav 72: 55-64.

Rodd-Henricks ZA, McKinzie DL, Crile RS, Murphy JM, McBride WJ (2000). Regional heterogeneity for the intracranial selfadministration of ethanol within the ventral tegmental area of female Wistar rats. Psychopharmacology (Berl) 149: 217-224.

Rossetti ZL, Hmaidan Y, Gessa GL (1992). Marked inhibition of mesolimbic dopamine release: a common feature of ethanol, morphine, cocaine and amphetamine abstinence in rats. Eur $J$ Pharmacol 221: 227-234.

Smith BR, Amit Z, Splawinsky J (1984). Conditioned place preference induced by intraventricular infusions of acetaldehyde. Alcohol 1: 193-195.

Tyndale RF, Pianezza ML, Sellers EM (1999). A common genetic defect in nicotine metabolism decreases risk for dependence and lowers cigarette consumption. Nicotine Tob Res 1(Suppl 2): S63-67, discussion S69-70.

Waller MB, McBride WJ, Lumeng L, Li TK (1982). Effects of intravenous ethanol and of 4-methylpyrazole on alcohol drinking in alcohol-preferring rats. Pharmacol Biochem Behav 17: 763-768.

Ward RJ, Colantuoni C, Dahchour A, Quertemont E, De Witte P (1997). Acetaldehyde-induced changes in monoamine and amino acid extracellular microdialysate content of the nucleus accumbens. Neuropharmacology 36: 225-232.

Weiss F, Parsons LH, Schulteis G, Hyytia P, Lorang MT, Bloom FE et al (1996). Ethanol self-administration restores withdrawalassociated deficiencies in accumbal dopamine and 5-hydroxytryptamine release in dependent rats. J Neurosci 16: 3474-3485.

Zimatkin SM, Lindros KO (1996). Distribution of catalase in rat brain: aminergic neurons as possible targets for ethanol effects. Alcohol Alcohol 31: 167-174. 